\title{
ASSESSMENT OF LEFT VENTRICULAR MECHANICS IN PATIENTS WITH ISCHEMIC HEART DISEASE
}

\author{
Natalia Gladkikh ${ }^{\mathrm{a} 1}$, Alexey Evtushenko ${ }^{1,2}$, Vladimir Evtushenko ${ }^{1,2}$, Elena Pavlyukova ${ }^{1}$ \\ ${ }^{1}$ Federal State Budgetary Scientific Institution "Research Institute for Cardiology", 634050, Tomsk, \\ Russia \\ ${ }^{2}$ National Research Tomsk Polytechnic University, 634050, Tomsk, Russia
}

\begin{abstract}
The paper presents new ultrasound technology for assessment of left ventricular (LV) strain in the longitudinal, radial, and circumferential directions and the LV area strain at rest and during dobutamine stressechocardiography in patients with intermediate pretest probability of ischemic heart disease (IHD). Analysis was performed for the first time using real-time three-dimensional echocardiography (4D Strain). It was shown that in patients with single-artery left anterior descending artery (LAD) and left circumflex coronary artery (LCX) stenosis of 50\% and more, the decreases in the global LV strain in the longitudinal, radial, and circumferential directions as well as in the LV strain area were observed at peak dobutamine stress in 4D Strain mode. Assessment of global LV strain in 4D Strain mode during dobutamine test had low sensitivity, specificity, and diagnostic accuracy in diagnosing single-vessel coronary artery disease.
\end{abstract}

\section{Assessment of left ventricular mechanics in patients with ischemic heart disease}

Myocardial strain is currently considered a parameter characterizing left ventricular (LV) contractility [1]. Assessment of global LV strain in the longitudinal direction has been widely implemented in clinical practice based on speckle tracking imaging technology (2D Strain) [2]. Recently, three-dimensional real time imaging (4D Strain) was developed for assessment of LV strain. This approach consists in speckle tracking in three dimensions through time which requires the absence of motions beyond a plane of scanning. Due to this, 4D Strain can be considered a natural extension of 2D Strain [3]. Advantages of 4D Strain over 2D Strain are obvious: lower time expenditure due to feasibility of single-step strain assessment in all directions: longitudinal, radial, and circumferential [4], as well as supposedly better accuracy due to the absence of the fallout effect $[3,5]$. Therefore, 4D Strain study seems promising for early diagnosis of IHD. However, there is currently a lack of works showing the sensitivity, specificity, and diagnostic accuracy of the myocardial strain assessment by stress echocardiography in 4D Strain mode.

\footnotetext{
${ }^{a}$ Corresponding author: gladkikh100@mail.ru
} 
The aim of our study was to assess the LV strain in the longitudinal, radial, and circumferential directions as well as the LV strain area in patients with intermediate pretest IHD probability by dobutamine stress echocardiography with real time three-dimensional imaging in 4D Strain mode.

\section{Materials and Methods}

The study comprised 59 patients $(41 \mathrm{men})$ aged $55.81 \pm 6.97$ years $(\mathrm{Me}=57.00$ years $)$ with suspected IHD who had intermediate pretest probability for IHD (46.56 $\pm 30.76 \%$; $\mathrm{Me}=32.40 \%$ ). Single-vessel coronary artery disease with stenosis of $50 \%$ and more was detected in $32(54.24 \%)$ out of 59 patients. Out of these patients, single-vessel coronary artery disease was diagnosed in 11 individuals with LAD stenosis, in 9 patients with RCA stenosis, and in 7 patients with LCX stenosis. Clinical characteristics are presented in Table 1.

Control group comprised 11 healthy volunteers $(8 \mathrm{men})$ aged $45.55 \pm 10.11$ years $(\mathrm{Me}=47.00$ years $)$. None of them were smokers and none presented with complaints characteristic for cardiovascular pathology. Healthy volunteers did not have arterial hypertension $(\mathrm{AH})$, obesity, abnormal blood lipids, carbohydrate metabolism disorders, cardiac rhythm and conduction disorders, and heart valve disease. Echocardiography was performed by using Vivid E9 cardiovascular ultrasound system (GE, Healthcare) in twodimensional mode according to standard method from parasternal (LV short axis views at annulus fibrosus of the mitral valve and at the apex) and apical (LV long axis 4- and 2chamber views) positions with M5S matrix array probe (1.5-4.8 MHz). Echocardiography parameters of patients with suspected IHD and of healthy volunteers are presented in Table 1. Real time three-dimensional images were acquired from apical position by using 4VD probe under the condition of simultaneous visualization of all walls of the left ventricle with 29 frames per second. Scanning was performed in Multi-Slice mode. To obtain cine-loop with optimal characteristics for post-processing, recording was done during six cardiac cycles at an expiratory breath hold to exclude bonding artefacts caused by breathing movements. Upon completion of automatic analysis, a dynamic 17-segment bulls-eye diagram was obtained for the LV strain in the longitudinal (GLS4D), radial (GRS4D), and circumferential (GCS4D) directions as well as for the strain area $\left(\mathrm{GAS}_{4 \mathrm{D}}\right)$ during cardiac cycle. Image was automatically frozen at the end of systole; as a result, we obtained the values of the global LV strain and the strains of individual segments including the LV apex.

Stress echocardiography was performed according to standard protocol. Assessments of commonly-accepted parameters, local contractility abnormalities in grayscale, and strain parameters in 4D Strain mode were performed at rest and at peak of dobutamine stress test.

\section{Statistical data analysis}

Testing the hypothesis of Gaussian distribution by Kolmogorov-Smirnov criteria in the form of Lilliefors and Shapiro-Wilk tests discarded this hypothesis. Therefore, the MannWhitney $\mathrm{U}$ test and the Wilcoxon test were performed. Correlation relationships between the pairs of qualitative variables were evaluated by using nonparametric Spearman's rank correlation coefficient. In all procedures of statistical analysis, the level of significance was chosen at 0.05 . The results are presented as $\mathrm{M} \pm \mathrm{SD}(\mathrm{M}$ is arithmetic mean, $\mathrm{SD}$ is mean root square deviation) and lower and upper quartiles. Sensitivity, specificity, and diagnostic accuracy were assessed by using standard formulas. 


\section{Results}

No clinically significant complications were observed during stress test. The images adequate for the analysis in 4D Strain mode at peak of dobutamine stress test were obtained from 69 patients. One patient was excluded from the analysis because of sub-optimal visualization of endocardial boundaries. Therefore, the feasibility rate of the method was $98.5 \%$.

The values of the global LV strain in the longitudinal, radial, and circumferential directions as well as the LV strain area in patients with coronary artery disease and in healthy volunteers are presented in Table 2. No significant differences in the values of $\mathrm{GLS}_{4 \mathrm{D}}, \mathrm{GCS}_{4 \mathrm{D}}, \mathrm{GRS}_{4 \mathrm{D}}$, and $\mathrm{GAS}_{4 \mathrm{D}}$ at rest between patients with single-vessel coronary artery disease and healthy volunteers were detected.

In dobutamine stress test, the global LV strain in the longitudinal, radial, and circumferential directions as well as the LV strain area in 4D Strain mode did not change in healthy individuals (Table 2) whereas, in the presence of LAD stenosis of $50 \%$ and more, we observed the decreases in $\mathrm{GLS}_{4 \mathrm{D}}, \mathrm{GRS}_{4 \mathrm{D}}, \mathrm{GCS}_{4 \mathrm{D}}$, and $\mathrm{GAS}_{4 \mathrm{D}}($ Table 2). Similar changes were observed in LCX disease (Table 2). Clinical case of dynamics in the LV strain in 4D Strain mode in dobutamine stress test in patient with angiographically-significant coronary atherosclerosis is presented in Figure 1.

In IHD patients with RCA disease, the LV strain in the longitudinal, radial, and circumferential directions as well as the strain area at peak of stress echocardiography did not significantly change (Table 2).

The LV strain in 4D Strain mode during dobutamine stress test showed low sensitivity, specificity, and diagnostic accuracy (Table 3). Similarly low sensitivity, specificity, and diagnostic accuracy were found for LAD, RCA, and LCX disease (Table 3). 


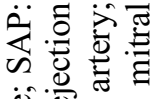

逍 光

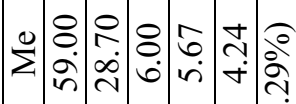

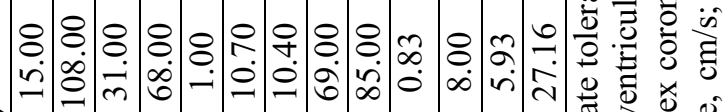

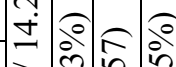

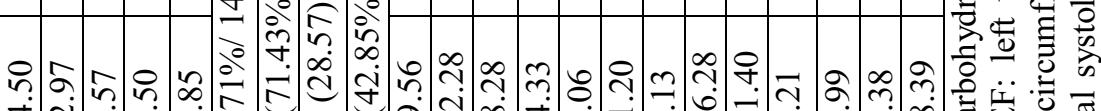

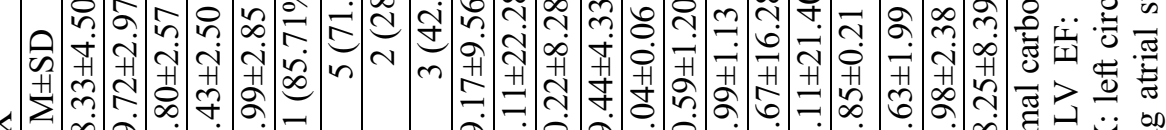

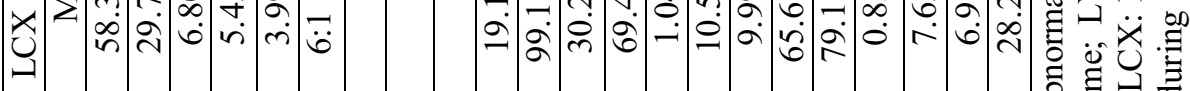

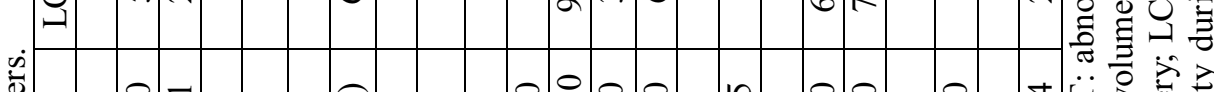

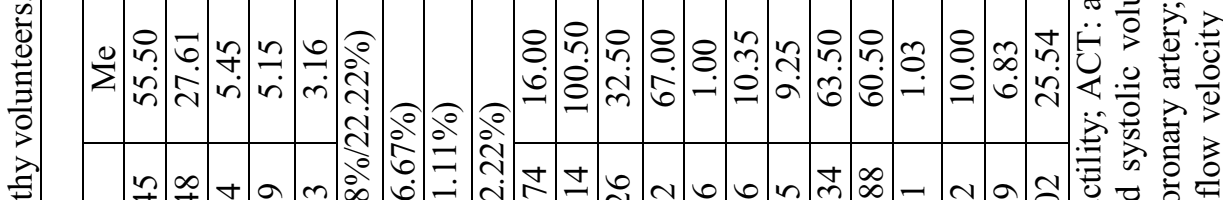

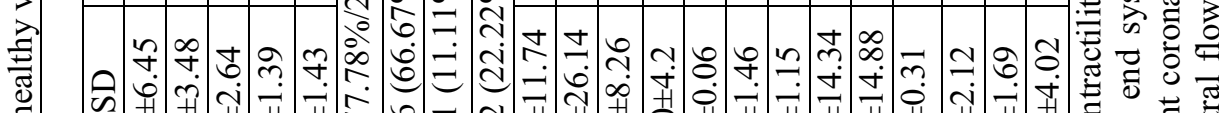

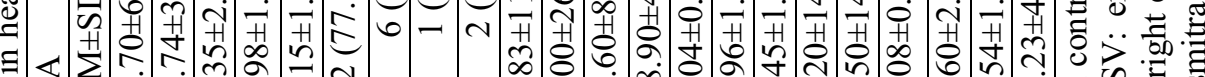

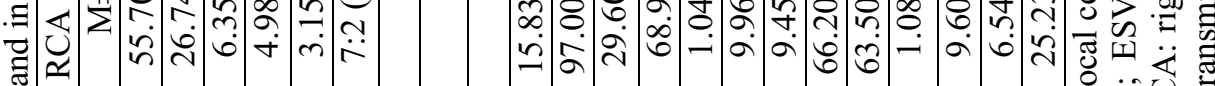

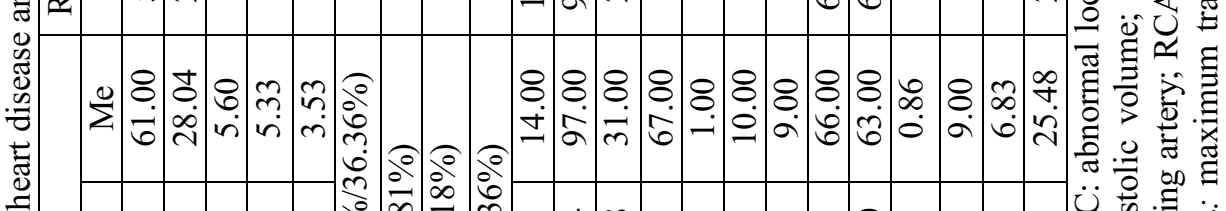

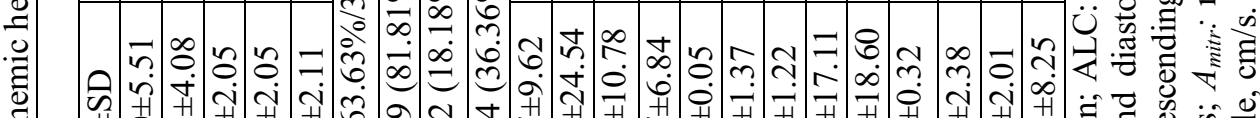

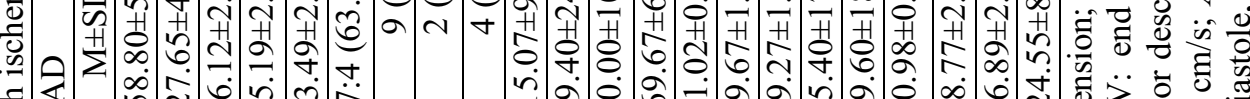

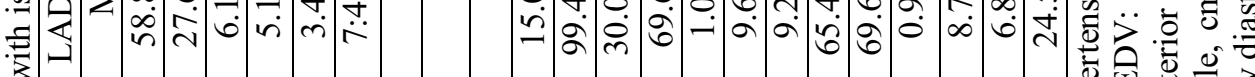

章

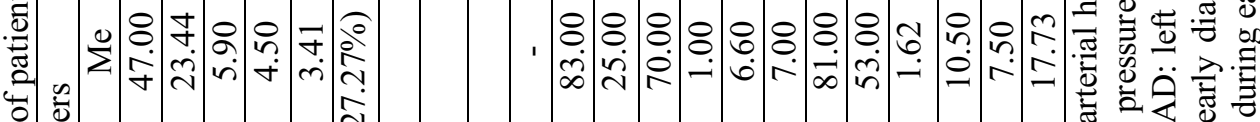

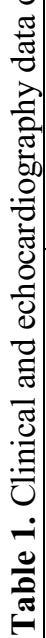

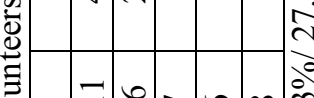

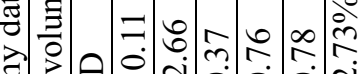

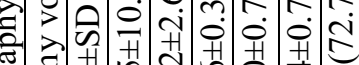

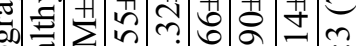

象

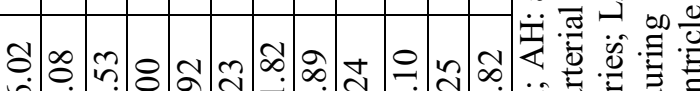
茾 茾 में

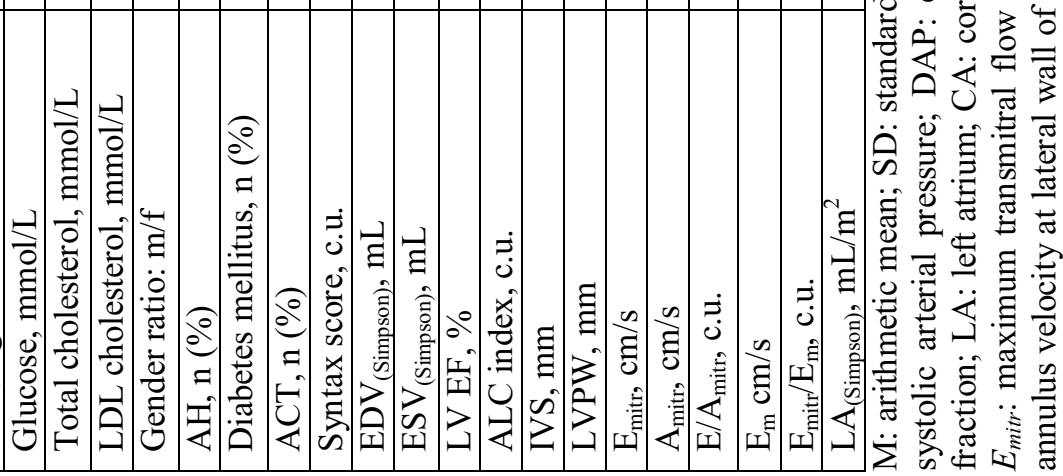




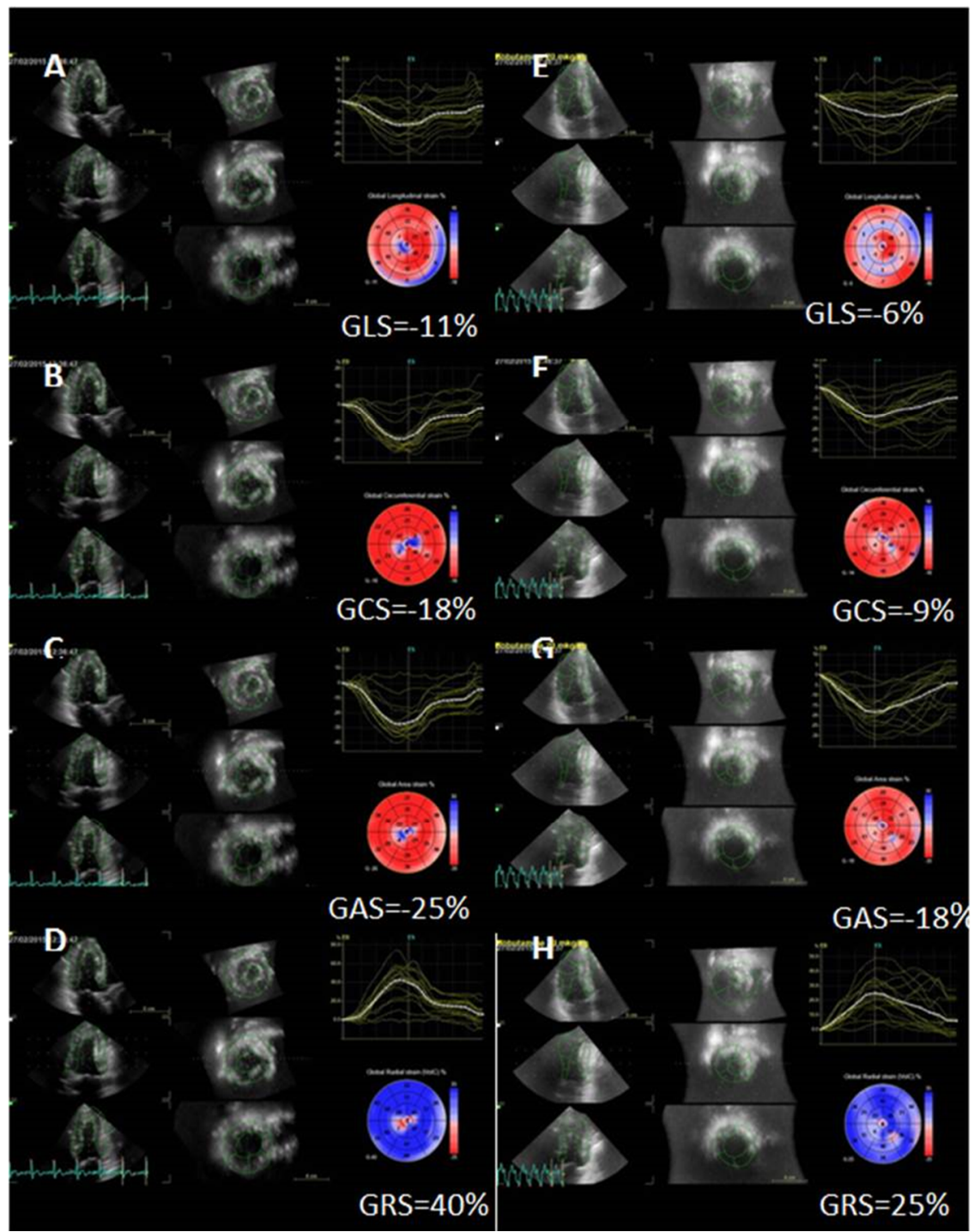

Figure 1. Clinical case. Patient $P, 61$ y.o., LCX stenosis of 70\%. Left ventricular strain at rest (A-D) and after infusion of $20 \mu \mathrm{g} / \mathrm{kg}(\mathrm{E}-\mathrm{H})$, heart rate of $134 \mathrm{bpm}$. Dynamics in the global and segmental LV strains in the longitudinal (A, E), circumferential (B, F), and radial (D, H) directions as well as in the strain area $(\mathrm{C}, \mathrm{G})$.

Table 2. Global left ventricular strain in 4D Strain mode at rest and during dobutamine stress echocardiography in patients with significant coronary artery disease and in healthy volunteers.

\begin{tabular}{|l|l|c|c|c|c|}
\hline \multicolumn{2}{|c|}{ Group } & GLS $_{4 \mathrm{D}}, \%$ & $\mathrm{GCS}_{4 \mathrm{D}}, \%$ & $\mathrm{GAS}_{4 \mathrm{D}}, \%$ & GRS $_{4 \mathrm{D}}, \%$ \\
\cline { 3 - 6 } & $\mathrm{M} \pm \mathrm{SD}$ & $\mathrm{M} \pm \mathrm{SD}$ & $\mathrm{M} \pm \mathrm{SD}$ & $\mathrm{M} \pm \mathrm{SD}$ \\
\hline $\begin{array}{l}\text { Healthy } \\
\text { volunteer } \\
\text { s }\end{array}$ & At rest & $-13.55 \pm 1.04$ & $-14.36 \pm 0.81$ & $-25.27 \pm 1.62$ & $37.09 \pm 3.11$ \\
\cline { 2 - 6 } & $\begin{array}{l}\text { Dobuta } \\
\text { mine }\end{array}$ & $-9.82 \pm 4.53$ & $-16.55 \pm 4.16$ & $-24.27 \pm 3.82 \& €$ & $\begin{array}{c}36.73 \pm 7.58 \\
£ ¥\end{array}$ \\
\hline LAD & At rest & $-11.15 \pm 3.96$ & $-16.60 \pm 5.13$ & $-24.20 \pm 6.55$ & $37.60 \pm 13.85$ \\
\hline
\end{tabular}




\begin{tabular}{|l|l|l|l|l|l|}
\hline & $\begin{array}{l}\text { Dobuta } \\
\text { mine }\end{array}$ & $-8.00 \pm 2.94 \#$ & $-13.30 \pm 3.74 \#$ & $-19.22 \pm 5.63 \# \&$ & $\begin{array}{c}28.30 \pm 9.42 \\
\# £\end{array}$ \\
\hline RCA & At rest & $-11.83 \pm 4.02$ & $-19.00 \pm 4.65$ & $-27.17 \pm 6.65$ & $44.00 \pm 14.81$ \\
\cline { 2 - 6 } & $\begin{array}{l}\text { Dobuta } \\
\text { mine }\end{array}$ & $-10.20 \pm 6.91$ & $-17.40 \pm 5.32$ & $-24.00 \pm 8.89$ & $39.60 \pm 16.07$ \\
\hline \multirow{2}{*}{ LCX } & At rest & $-10.25 \pm 3.92$ & $-15.75 \pm 4.53$ & $-23.25 \pm 6.20$ & $34.88 \pm 13.13$ \\
\cline { 2 - 6 } & $\begin{array}{l}\text { Dobuta } \\
\text { mine }\end{array}$ & $-7.13 \pm 3.79 \#$ & $-13.13 \pm 3.98 \#$ & $-18.13 \pm 6.58 \# €$ & $\begin{array}{c}26.00 \pm 11.83 \\
\# ¥\end{array}$ \\
\hline
\end{tabular}

$\# p<0.05$ compared with the values at rest; $£ U=27.000, Z_{\text {adj }}=-2.151, p=0.03 ; \S U=11.000$, $Z_{\text {adj }}=-2.376, p=0.017 ; € U=19.000, Z_{\text {adj }}=2.224, p=0.02 ; ¥ U=19.000, Z_{\text {adj }}=-2.198, p=0.02$.

Table 3. Sensitivity, specificity, and diagnostic accuracy of the parameters of left ventricular strain in 4D Strain mode in detection of coronary atherosclerosis by dobutamine stress echocardiography.

\begin{tabular}{|c|c|c|c|c|c|c|}
\hline $\begin{array}{l}\text { Paramete } \\
\mathrm{r}\end{array}$ & \multicolumn{2}{|c|}{ Sensitivity, $\%$} & \multicolumn{2}{|c|}{ Specificity, \% } & \multicolumn{2}{|c|}{$\begin{array}{l}\text { Diagnostic accuracy, } \\
\%\end{array}$} \\
\hline & Strain & ALC & Strain & ALC & Strain & ALC \\
\hline \multicolumn{7}{|c|}{ Stenosis over $50 \%$} \\
\hline $\mathrm{GLS}_{4 \mathrm{D}}$ & 62.50 & \multirow{4}{*}{33.33} & 21.05 & \multirow{4}{*}{89.79} & 50.74 & \multirow{4}{*}{72.86} \\
\hline $\mathrm{GCS}_{4 \mathrm{D}}$ & 57.44 & & 31.57 & & 50.00 & \\
\hline $\mathrm{GAS}_{4 \mathrm{D}}$ & 68.08 & & 27.77 & & 56.92 & \\
\hline $\mathrm{GRS}_{4 \mathrm{D}}$ & 66.67 & & 31.57 & & 56.71 & \\
\hline
\end{tabular}

LAD stenosis over $50 \%$

\begin{tabular}{|l|l|}
\hline GLS $_{4 \mathrm{D}}$ & 78.57 \\
\hline $\mathrm{GCS}_{4 \mathrm{D}}$ & 64.28 \\
\hline $\mathrm{GAS}_{4 \mathrm{D}}$ & 69.23 \\
\hline $\mathrm{GRS}_{4 \mathrm{D}}$ & 64.28 \\
\hline
\end{tabular}

26.67

\begin{tabular}{|l|}
\hline 35.84 \\
\hline 40.38 \\
\hline 30.76 \\
\hline 32.07 \\
\hline
\end{tabular}

85.45

\begin{tabular}{|l|}
\hline 44.78 \\
\hline 50.00 \\
\hline 38.46 \\
\hline 35.82 \\
\hline
\end{tabular}

RCA stenosis over $50 \%$

\begin{tabular}{|l|l|}
\hline $\mathrm{GLS}_{4 \mathrm{D}}$ & 75.00 \\
\hline $\mathrm{GCS}_{4 \mathrm{D}}$ & 62.50 \\
\hline $\mathrm{GAS}_{4 \mathrm{D}}$ & 75.00 \\
\hline $\mathrm{GRS}_{4 \mathrm{D}}$ & 62.50 \\
\hline
\end{tabular}

40

\begin{tabular}{|l|}
\hline 33.89 \\
\hline 39.65 \\
\hline 31.57 \\
\hline 32.20 \\
\hline
\end{tabular}

86.67

\begin{tabular}{|l|}
\hline 38.80 \\
\hline 42.42 \\
\hline 36.92 \\
\hline 37.35 \\
\hline
\end{tabular}

LCX stenosis over $50 \%$

\begin{tabular}{|l|l|}
\hline $\mathrm{GLS}_{4 \mathrm{D}}$ & 77.78 \\
\hline $\mathrm{GCS}_{4 \mathrm{D}}$ & 66.67 \\
\hline $\mathrm{GAS}_{4 \mathrm{D}}$ & 77.78 \\
\hline $\mathrm{GRS}_{4 \mathrm{D}}$ & 66.67 \\
\hline
\end{tabular}

\begin{tabular}{|l|}
\hline 34.48 \\
\hline 40.35 \\
\hline 32.14 \\
\hline 32.75 \\
\hline
\end{tabular}

88.52

\begin{tabular}{|l|}
\hline 40.29 \\
\hline 43.93 \\
\hline 40.00 \\
\hline 37.71 \\
\hline
\end{tabular}

84.28

\section{Discussion}

As of today, national and foreign literature lacks data on the use of 4D Strain mode in stress echocardiography. It is worthy to note that only a few publications report data on the strain assessment by stress echocardiography in 2D Strain mode. Data of clinical and experimental studies demonstrate the possibility of assessing the parameters of the myocardial strain in stress echocardiography [6-8]. There is evidence that assessments of longitudinal and radial strains with Tissue Doppler Imaging $[6,9]$ are sensitive to ischemia. 
According to experimental data, the strain in the longitudinal, radial, and circumferential directions increases at peak of stress test in the absence of ischemia [10]. The experiments show that a decrease in the strain in these directions is not observed in stress echocardiography in the presence of hemodynamically insignificant coronary artery stenosis. The presence of hemodynamically significant stenosis leads to a decrease in the strain by $39 \%$ in the longitudinal, by $28 \%$ in the radial, and by $26 \%$ in the circumferential directions [10]. Kodali V. et al. demonstrated that assessment of two-dimensional strain in longitudinal direction by dobutamine stress echocardiography shows higher sensitivity compared with expert evaluation of abnormal local contractility at global deformation critical level of $-8 \%$ [11]. Data concerning dynamics of the LV strain in 4D Strain mode at peak of stress tests are occasional in literature [12]. Based on theoretical advantages of the method, we hypothesized that the strain assessment in 4D Strain mode is more sensitive to changes in inotropic function of the left ventricle compared with the values of 2D Strain. We observed a decrease in the parameters of global LV deformation in 4D Strain mode in patients with angiographically significant coronary artery stenosis. Takano M. et al. [13] also observed a decrease in the values of 4D Strain in adenosine stress echocardiography and it was considered a sign of myocardial ischemia. According to these data, sensitivity and specificity of 4D Strain mode were $62.5 \%$ and $83.6 \%$, respectively [13]. Authors of this publication believe that the values of the circumferential LV strain are more adequate for a detection of myocardial ischemia. We obtained lower values of sensitivity and specificity and, accordingly, of diagnostic accuracy for the strain assessment in 4D Strain mode. However, Takano M. et al. considered coronary artery stenosis significant if it was over $75 \%[13]$.

It is necessary to note that myocardial strain is reflective of contractility of the part or of the entire left ventricle i.e. it is reflective of the LV function whereas the presence of coronary artery stenosis according to data of coronary angiography merely demonstrates angiographic significance of stenosis and its potential ability to limit coronary flow to the part of the LV myocardium. A true hemodynamic significance of coronary artery stenosis can be determined based on the assessment of fractional flow reserve [14]. Limitation of our study was the lack of opportunity to determine this parameter. Perhaps, diagnostic accuracy of the LV strain assessment including that in 4D Strain mode is higher in regard to a detection of coronary atherosclerosis as an anatomical substrate.

\section{Conclusions}

In patients with single-vessel LAD and LCX stenosis of 50\% and more, decreases in the global LV strain in the longitudinal, radial, and circumferential directions as well as in the LV strain area were observed at peak of dobutamine stress echocardiography. The global LV strain in 4D Strain mode in dobutamine stress echocardiography had low sensitivity, specificity, and diagnostic accuracy. Unfortunately, we have not performed dobutamine stress echocardiography in patients with a high pretest probability of IHD, because there are not indications for functional tests for these patients, according to the ESC/EACTS Guidelines on myocardial revascularization (2014). We believe that the sensitivity, specificity and diagnostic accuracy will be much higher if this group of patients will be examined. 


\section{Acknowledgements}

The study was supported by a grant from the Russian Science Foundation (№ 15-1510016), and the program of improving competitiveness of the TSU (project No. 8.2.31.2015).

\section{References}

[1] G. R. Sutherland, L. Hatle, P. Claus, J. D'hooge, B. H. Bijnens, Doppler myocardial imaging (BSWK-Hassel, Zagreb, 2006)

[2] R. M. Lang, L. P. Badano, V. Mor-Avi, J. Afilalo, A. Armstrong, L. Ernande, F. A. Flachskampf, E. Foster, S. A. Goldstein, T. Kuznetsova, P. Lancellotti, D. Muraru, M. H. Picard, E. R. Rietzschel, L. Rudski, K. T. Spencer, W. Tsang, J.-U. Voigt, J Am Soc Echocardiogr. 28, 1 (2015) doi: 10.1016/j.echo.2014.10.003

[3] V. C.-C. Wu, M. Takeuchi, K. Otani, N. Haruki, H. Yoshitani, M. Tamura, H. Abe, F.-C. Lin, Y. Otsuji, J Am Soc Echocardiogr. 26, 1274 (2013) doi: 10.1016/j.echo.2013.07.006

[4] S. Buccheri, I. Monte, S. Mangiafico, V. Bottari, S. Leggio, C. Tamburino, BioMed Research Intern. 2013, 297895 (2013) doi: 10.1155/2013/297895

[5] J. A. Urbano-Moral, A. R. Patel, M. S. Maron, J. A. Arias-Godinez , N.G. Pandian, Echocardiography 29, 997 (2012) doi: 10.1111/j.1540-8175.2012.01773.x

[6] C. B. Ingul, A. Stoylen, S. A. Slordahl, R. Wiseth, M. Burgess, T.H. Marwick, JACC 49, 1651 (2007) doi: 10.1016/j.jacc.2007.01.059

[7] G. Derumeaux, M. Ovize, J. Loufoua, X. André-Fouet, Y. Minaire, A. Cribier, B. Letac, Circulation 97, 1970 (1998)

[8] J. Gorcsan, D. P. Strum, W. A. Mandarino, V. K. Gulati, M. R. Pinsky, Circulation 95, 2423 (1997)

[9] B. H. Amundsen, T. Helle-Valle, T. Edvardsen, H. Torp, J. Crosby, E. Lyseggen, A. Støylen, H. Ihlen, J. A. C. Lima, O. A. Smiseth, S. A. Slørdahl, JACC 47, 789 (2006) doi: 10.1016/j.jacc.2005.10.040

[10] P. Reant, L. Labrousse, S. Lafitte, P. Bordachar, X. Pillois , L. Tariosse , S. Bonoron-Adele , P. Padois , C. Deville, R. Roudaut, P. Dos Santos, JACC 51, 149 (2008) doi: 10.1016/j.jacc.2007.07.088

[11] V. Kodali, S. K. Saha, K. Parcham-Azad, R. S. Toole, A. S. Gopal, JACC 57, E. 767 (2011)

[12] P. Reant, L. Labrousse, S. Lafitte, L. Tariosse, S. Bonoron-Adele, P. Padois, R. Roudaut, P. Dos Santos, and A. DeMaria, J Am Soc Echocardiogr. 23, 95 (2010) doi: 10.1016/j.echo.2009.10.001

[13] M. Iwai-Takano, T. Watanabe, JACC 61, E. 1019 (2013)

[14] S. Windecker, P. Kolh, F. Alfonso, J.-P. Collet, J. Cremer, V. Falk, G. Filippatos, C. Hamm, S. J. Head, P. Jüni, A. P. Kappetein, A. Kastrati, J. Knuuti, U. Landmesser, G. Laufer, F.-J. Neumann, D. J. Richter, P. Schauerte, M. S. Uva, G. G. Stefanini, D. P. Taggart, L. Torracca, M. Valgimigli, W. Wijns, and A. Witkowski, Eur Heart J. . 35, 2541 (2014) doi:10.1093/eurheartj/ehu278 